\title{
SIMULATION OF SOIL WATER MOVEMENT UNDER BIOCHAR APPLICATION BASED ON THE HYDRUS-1D IN THE BLACK SOIL REGION OF CHINA
}

\author{
WU, Y. ${ }^{1,2}-$ YANG, A. ${ }^{3}-$ ZHAO, Y. $^{1 *}-$ LIU, Z. $^{4}$ \\ ${ }^{I}$ College of Forestry, Northeast Forestry University, Harbin, China \\ ${ }^{2}$ Heilongjiang Agricultural Reclamation Survey Design and Research Institute \\ No. 270, Ganshui Road, Xiangfang District, Harbin City, Heilongjiang Province, Harbin, China \\ (e-mail: 55206522@qq.com; phone: +86-137-9663-5002-Y. Wu) \\ ${ }^{3}$ Department of Plant and Environmental Sciences, Faculty of Science University of Copenhagen, \\ Højbakkegård Allé 13, DK-2630 Tåstrup, Denmark \\ ${ }^{4}$ College of Water Conservancy and Architecture, Northeast Agricultural University \\ Harbin, China \\ *Corresponding author \\ e-mail: zhaoys1957@163.com; phone: +86-138-0481-7158
}

\begin{abstract}
.
(Received $9^{\text {th }}$ Dec 2018; accepted $4^{\text {th }}$ Mar 2019)

The soil water movement under different biochar treatments of the black soil region in Northeast China was simulated by the Hydrus- $1 \mathrm{~d}$ software in this paper. The simulation errors were between $-5.12 \%$ and $9.15 \%$, within the $\pm 10 \%$ range. with the increasing amount of biochar applied, the residual soil moisture content and the shape parameter were decreasing, while the saturated soil moisture content and the reciprocal of air inlet value were increasing. The difference between the saturated and residual water content was getting bigger with the increasing amount of biochar applied, which improved the available soil moisture content, a beneficial factor of crop growth. With increasing the amount of biochar applied, the moisture rate in the soil profile clearly increased, soil water redistribution curve right shifted significantly, which indicated that biochar can greatly improve the water retention ability of the soil. Furthermore, the soil moisture content increased when the soil depth was more than $50 \mathrm{~cm}$. The effects of biochar on soil moisture diminished rapidly.
\end{abstract}

Keywords: farmland, Northeast China, soil water distribution, simulation model application, biochar application

\section{Introduction}

Hydrus-1d is a software for the simulation of water, energy and solute movements in saturated and unsaturated porous media, developed by US Salinity laboratory. It has been widely used in the analysis of the processes of water movement and solute migration in unsaturated and porous media. Simunek et al. (1999) and Simunek et al. (1996) used it to calculate the parameters of soil water movement and solute migration. Tang et al. (2011) simulated the soil water infiltration process of the snow melting in the desert region based on the Hydrus-1d, and the simulation deviation was small. Chi et al. (2014) used the modified Richards equation to simulate soil water infiltration and solute migration processes. Ma et al. (2011) studied field water cycle regularities in Huabei Plain by means of Hydrus-1d, and the simulation precision of the model was high. Liu et al. (2018) simulated the soil water infiltration process for different soils, and revealed the relationship between the soil water distribution, soil types, and amount and rate of irrigation water after $24 \mathrm{~h}$ of irrigation. 
Biochar is a substance in the state of solid particles, which is produced from some wastes such as crop straw, animal manure, etc. under high-temperature and hypoxia (Wei et al., 2018b). Many studies showed that biochar application could both increase and decrease the bulk density and the total porosity of the soil separately, and these changes could affect its water capacity (Wei et al., 2018a). Furthermore, due to the higher moisture absorption ability of biochar, soil water capacity could be increased (Xiao et al., 2015; Qi et al., 2014), along with the improvement of plant growth (Oguntunde et al., 2008). In addition, it also could affect soil organic matter, aggregate, $\mathrm{pH}$ value, etc. to some extent. It would also be possible to influence soil water diffusivity, dispersion coefficient and unsaturated hydraulic conductivity significantly, which in turn would affect soil water storage and movement (Mukherjee et al., 2013; Mankasingh et al., 2011; Novak et al., 2012; Wei et al., 2016; George et al., 2012; Li et al., 2014). As a result of previous studies some researchers are turning their attention towards the effects of biochar on soil water movement. When biochar is applied to clay, the soil water contents, soil water infiltration rates and accumulated infiltration water amount could all be increased (Cen et al., 2016). By changing the amount of biochar soil water infiltration rate and the amount of accumulated infiltration water were influenced at varying rates under different salinization degrees (Liu et al., 2017). When the soil moisture content was lower than $0.4 \mathrm{~cm}^{3} / \mathrm{cm}^{3}$, biochar could lower the soil water diffusivity, and when it was higher than $0.4 \mathrm{~cm}^{3} / \mathrm{cm}^{3}$, the results were the opposite (Liu, 2017). Few researches have studied and simulated soil water movement in the black soil region of China, and this research could prove helpful for soil water management in the region.

The soil water movement simulation and analysis in this paper would provide a basis for the efficient utilization of soil and water resources, and the protection of the black soil region in northeastern part of China.

\section{Materials and methods}

\section{The experimental area}

The experiment area was located in a sloping farmland with a 3 degree slope gradient in the Hongxing state farm of Heilongjiang province, China (Fig. 1).

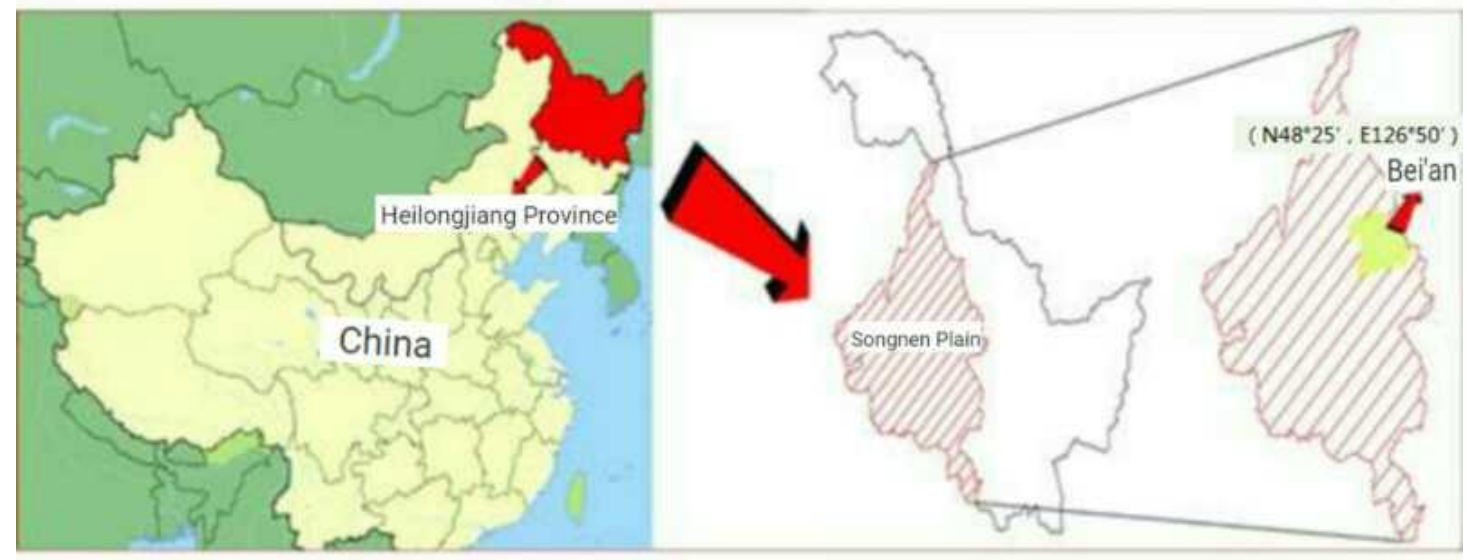

Figure 1. Location of the experimental site 
The soil type was meadow black soil with $21.93 \%$ of sand $(>0.02 \mathrm{~mm}), 44.21 \%$ of silt $(0.02 \sim 0.002 \mathrm{~mm})$ and $33.86 \%$ of clay $(<0.002 \mathrm{~mm})$ in mass fractions, $86.3 \mathrm{~g} / \mathrm{kg}$ organic matter content, $18.5 \mathrm{mg} / \mathrm{kg}, 18.5 \mathrm{mg} / \mathrm{kg}$ of ammonium nitrogen, $58.5 \mathrm{mg} / \mathrm{kg}$ of available phosphorus, $151 \mathrm{mg} / \mathrm{kg}$ of available potassium, and the $\mathrm{pH}$ value was 6.3 (Wei et al., 2016). The raw material of the biochar was corn straw and was purchased from the Jinhefu agricultural development company of Liaoning province near the experimental site. It was formulated under $450{ }^{\circ} \mathrm{C}$ temperature and anaerobic conditions. The particle size of the biochar was $1.5 \sim 2.0 \mathrm{~mm}$, the contents of total $\mathrm{C}$, total $\mathrm{N}$, total $\mathrm{P}$ and total $\mathrm{K}$ were $70.21 \%, 1.58 \%, 0.73 \%$ and $1.66 \%$ respectively, and the $\mathrm{pH}$ value was 9.36 (Wei et al., 2016).

\section{Experimental design}

Five different amounts of biochar were applied $\left(0,25,50,75\right.$ and $\left.100 \mathrm{t} / \mathrm{hm}^{2}\right)$ in different field plots with $5 \mathrm{~m}$ of width and $20 \mathrm{~m}$ of length, named CK, C1, C2, C3 and $\mathrm{C} 4$ treatments respectively, among which CK was the control treatment.

Before seeding, the top $0-25 \mathrm{~cm}$ of the soil layer was loosened, followed by the artificial mixing of biochar into the soil, after which a waiting period took place until the seeding of the soybeans. The soybean variety used was Heihe number 3.

The fertilizer supply was as follows; NPK compound fertilizer with $13 \%$ of N, $25 \%$ of $\mathrm{P}_{2} \mathrm{O}_{5}$ and $10 \%$ of $\mathrm{K}_{2} \mathrm{O}$ was supplied at the seeding stage, with a supply amount of 450 $\mathrm{Kg} / \mathrm{hm}^{2}$.

\section{The items and methods of the observations}

Soil matric potential was measured using tensionmeters installed in the soil layers at $10,20,40,60,80,100,120$ and $140 \mathrm{~cm}$ below soil surface.

Meteorological data was measured using automatic weather station located in the experimental site.

Soil water content was measured using the TRIME-T3 Pipe Soil Moisture Measurement System made in Germany.

\section{Simulation calculation}

\section{Brief introduction of Hydrus-1d}

Hydrus-1d is a model annunciated by the international center of ground water simulation (Liu et al., 1998) with 5 modules used for different calculations, including water movement, solution migration, heat conduction, plant-root water uptake and plantroot growth. The water movement module can be specifically used for unsaturated soil water movement simulation, and not only does it take plant-root water uptake into consideration, but also modifies the lagging of soil water holding capacity. It's widely used in soil water movement simulation (Wang et al., 2005, 2012; Lai et al., 2015) and the results are more precise. The boundary conditions of the model are comprehensive, in which the upper boundary conditions include constant water head, constant water flow, atmospheric boundary, variable water head, variable water flow and atmospheric boundary condition surface with run-off; while the lower boundary conditions include constant water head, constant water flow, variable water head, variable water flow, freedom drainage, deep layer drainage, leached surface and horizontal drainage. Some boundary conditions are variable-boundaries and correspondent variable conditions should be imputed. 
For the calculation of water movement the classical equation of Richards was used, taking the soil surface as the abscissa while the direction of the $Z$ axis is downwards, then the basic equation of unsaturated soil water movement is as follows.

$$
\frac{\partial \theta}{\partial t}=\frac{\partial}{\partial \mathbf{z}}\left(D(\theta) \frac{\partial h}{\partial z}\right)+\frac{\partial k(\theta)}{\partial z}+S
$$

Where $\theta$ is soil water content; $h$ is suction head; $k$ is unsaturated soil water conductivity; $S$ is plant-root water uptake, which would be 0 when no plants are present in the soil surface; and $D(\theta)$ is soil water diffusivity.

The model can be divided into a single pore model and a double pore model, and the Van Genuchten-Mualem model which was developed from the single models of Van Genuchten (1980) and Mualem (1975), its basic equation is as follows:

$$
\theta(h)=\left\{\begin{array}{l}
\theta_{r}+\frac{\theta_{s}-\theta_{r}}{\left(1+|\alpha h|^{n}\right)^{m}}, h<0 \\
\theta_{s}, h \geq 0
\end{array}\right.
$$

Where, $\theta_{r}$ is the residual soil moisture content; $\theta_{s}$ is saturated soil moisture content; $h$ is pressure water head.

Considering the effect of suction head on plant-root water uptake, Feddes function was used to calculate the actual transpiration rate according to the potential transpiration rate. Its basic equation is as follows:

$$
\alpha(h)=\left\{\begin{array}{l}
0, h \geq h_{4}, h \leq h_{1} ; \\
\frac{h_{1}-h}{h_{1}-h_{2}}, h_{2} \leq h \leq h_{1} ; \\
1, h_{3} \leq h \leq h_{2} ; \\
\frac{h-h_{4}}{h_{3}-h_{4}}, h_{4} \leq h \leq h_{3} ;
\end{array}\right.
$$

Where, $h$ is soil water potential, $\mathrm{cm} ; h_{1}$ is the negative pressure value when the soil pores are full of water; $h_{2}$ is a negative value when the soil water reaches the water holding capacity; $h_{3}$ is a negative value when the capillary bond is disrupted due to plant consumption and evaporation from the soil surface; and $h_{4}$ is a negative pressure value when permanent wilting occurs.

\section{Definite conditions}

1) Initial conditions

The initial condition is the negative pressure value of every soil layer in the beginning. 


$$
h(z, 0)=h_{0}(z), z \geq 0
$$

2) Boundary condition

The experimental plots were in a sloping farm land with a 3 degree gradient, thus the soil surface boundary condition was:

$$
-\left.K \frac{\partial h}{\partial z}\right|_{\tau 1}=q(z, t)
$$

There should be no surface water when the rain intensity is lower than the infiltration intensity, which is:

$$
-k(\theta)\left(\frac{\partial \theta}{\partial z}+1\right)=R(t), z>0
$$

And surface water will accumulate when the rain intensity is higher than the infiltration intensity, which is:

$$
h(0, t)=H(t), t>0, z=0
$$

Where, $q(z, t)$ is the water flux density in the soil surface boundary; $R(t)$ is the rain intensity; and $H(t)$ is the depth of surface water.

The parameters to be measured are residual soil moisture content $\theta_{r}$; saturated soil moisture content $\theta_{s}$; reciprocal of air-entry value a and shape factor $n$; soil water content $\theta$; pressure water head $h$; saturated water conductivity $K_{S}$; soil texture and soil layer thickness $d$; inclined degree of soil layer; times at which the simulation is started and finished, etc..

The above soil hydraulic parameters were obtained from soil water characteristic curves which were determined using a Hitachi CR-21G3 centrifuge manufactured in Japan. 8 levels of speed were set $(500,1000,1500,2000,3000,4000,5000$ and $6000 \mathrm{r} / \mathrm{min}$ ), and the centrifugal time for each speed level was $100 \mathrm{~min}$. Ks was measured with the double-rings method in the field plots, and the $K_{S}$ value was calculated according to Daxi law, $K_{S}=0.75 \mathrm{~cm} / \mathrm{h}$.

Unsaturated soil water conductivity was determined with the following equation:

$$
K(\theta)=K_{s}\left(\frac{\theta-\theta_{r}}{\theta_{s}-\theta_{r}}\right)^{0.5}\left\{1-\left[1-\left(\frac{\theta-\theta_{r}}{\theta_{s}-\theta_{r}}\right)^{1 / m}\right]^{m}\right\}^{2}
$$

The water diffusivity $D(\theta)$ was determined using an infiltration method of horizontal columns. 


\section{Results and analysis}

\section{Soil hydraulic characteristic parameters}

Soil water holding capacity is reflected in the soil water characteristic curves. The Van Genuchten model in Hydrus-1d had good fitting effects for the experimental area (Liu, 2017; Wang, 2016), thus it was used to fit the soil water characteristic curve of every treatments. The fitting results of soil hydraulic characteristic parameters was shown in Table 1. The VG model was more effective, the fitting precision was higher than 0.995 , the values of RMSE for every treatment ranged from 0.516 to 1.219 , thus all the parameters can be used for soil water movement simulation.

With the increase of the amount of biochar applied, the residual soil moisture content and the shape parameter were decreasing, while the saturation moisture content and the reciprocal of air inlet value were increasing. The difference between the saturated and residual water content were getting higher with increasing the amount of biochar applied, which greatly improved the available soil moisture content, a beneficial factor for crop growth.

Table 1. Parameters for the Van Genuchten model

\begin{tabular}{c|c|c|c|c|c|c}
\hline Treatment & $\begin{array}{c}\text { Residual soil } \\
\text { water content } \boldsymbol{\theta}_{\boldsymbol{r}} \\
\left(\mathbf{c m}^{\mathbf{3}} \mathbf{c m}^{-\mathbf{3}} \mathbf{r}\right.\end{array}$ & $\begin{array}{c}\text { Saturated soil } \\
\text { water content } \boldsymbol{\theta}_{\boldsymbol{s}} \\
\left(\mathbf{( m}^{\mathbf{3}} \mathbf{c m}^{-\mathbf{3}} \mathbf{s}\right.\end{array}$ & $\begin{array}{c}\text { Reciprocal of air } \\
\text { inlet value a } \\
\left(\mathbf{( m}^{-\mathbf{1}} \mathbf{)}\right.\end{array}$ & $\begin{array}{c}\text { Shape } \\
\text { parameter } \boldsymbol{n}\end{array}$ & Fitting goodness $\boldsymbol{R}^{\mathbf{2}}$ & RMSE \\
\hline $\mathrm{CK}$ & 0.10787 & 0.42188 & 0.00818 & 1.66675 & 0.9956 & 0.852 \\
$\mathrm{C} 1$ & 0.10712 & 0.43591 & 0.00918 & 1.61491 & 0.9972 & 1.295 \\
$\mathrm{C} 2$ & 0.08200 & 0.45146 & 0.01166 & 1.47769 & 0.9995 & 0.516 \\
$\mathrm{C} 3$ & 0.08061 & 0.47913 & 0.01416 & 1.45699 & 0.9996 & 0.793 \\
$\mathrm{C} 4$ & 0.07313 & 0.48606 & 0.01506 & 1.41372 & 0.9995 & 1.141 \\
\hline
\end{tabular}

\section{Model validation}

The CK treatment and the rain with $26 \mathrm{~mm}$ of total rain-water and $2 \mathrm{~h}$ duration occurred on the $22^{\text {nd }}$ of July 2015 were chosen for the model validation. Compare the actual soil water redistribution curves and their simulation results, and calculate their errors to check the model's reliability and accuracy. Figure 2 shows the soil water redistribution at $20 \mathrm{~min}, 12 \mathrm{~h}, 24 \mathrm{~h}$ and $48 \mathrm{~h}$ after rain and their simulations. The actual value and simulation value were close.

The simulation errors were showed in Table 2. The simulation errors were between $5.12 \%$ and $9.15 \%$ which were within $\pm 10 \%$. The results showed that the simulation model was reliable and accurate, and that the model could be used for soil movement simulation.

Table 2. Simulated and measured soil water redistribution data and its errors

\begin{tabular}{|c|c|c|c|c|c|c|}
\hline \multirow{2}{*}{$\begin{array}{c}\text { Depth } \\
(\mathrm{cm})\end{array}$} & \multicolumn{2}{|c|}{20 min } & \multirow{2}{*}{$\begin{array}{c}\text { Errors } \\
(\%)\end{array}$} & \multicolumn{2}{|c|}{$12 \mathrm{~h}$} & \multirow{2}{*}{$\begin{array}{c}\text { Errors } \\
(\%)\end{array}$} \\
\hline & Measured & Simulated & & Measured & Simulated & \\
\hline 10 & 0.3391 & 0.3540 & $4.39 \%$ & 0.3412 & 0.3261 & $-4.43 \%$ \\
\hline 20 & 0.311 & 0.3205 & $3.05 \%$ & 0.3021 & 0.3294 & $9.04 \%$ \\
\hline 40 & 0.3082 & 0.3036 & $-1.49 \%$ & 0.3381 & 0.3303 & $-2.31 \%$ \\
\hline 60 & 0.2913 & 0.3016 & $3.54 \%$ & 0.3083 & 0.3252 & $5.48 \%$ \\
\hline 80 & 0.3059 & 0.2996 & $-2.06 \%$ & 0.3278 & 0.3177 & $-3.08 \%$ \\
\hline 100 & 0.2921 & 0.2976 & $1.88 \%$ & 0.3010 & 0.3131 & $4.02 \%$ \\
\hline
\end{tabular}


Table 2. (cont.) Simulated and measured soil water redistribution data and its errors

\begin{tabular}{|c|c|c|c|c|c|c|}
\hline \multirow{2}{*}{$\begin{array}{c}\text { Depth } \\
\text { (cm) }\end{array}$} & \multicolumn{2}{|c|}{$24 \mathrm{~h}$} & \multirow{2}{*}{$\begin{array}{c}\text { Errors } \\
(\%)\end{array}$} & \multicolumn{2}{|c|}{$48 \mathrm{~h}$} & \multirow{2}{*}{$\begin{array}{c}\text { Errors } \\
(\%)\end{array}$} \\
\hline & Measured & Simulated & & Measured & Simulated & \\
\hline 10 & 0.3021 & 0.3130 & $3.61 \%$ & 0.2921 & 0.301 & $3.05 \%$ \\
\hline 20 & 0.2981 & 0.3168 & $6.27 \%$ & 0.3221 & 0.3044 & $-5.50 \%$ \\
\hline 40 & 0.3381 & 0.3208 & $-5.12 \%$ & 0.2964 & 0.3099 & $4.55 \%$ \\
\hline 60 & 0.3253 & 0.3222 & $-0.95 \%$ & 0.3263 & 0.3139 & $-3.80 \%$ \\
\hline 80 & 0.3301 & 0.3221 & $-2.42 \%$ & 0.3138 & 0.3164 & $0.83 \%$ \\
\hline 100 & 0.3171 & 0.3217 & $1.45 \%$ & 0.2907 & 0.3173 & $9.15 \%$ \\
\hline
\end{tabular}

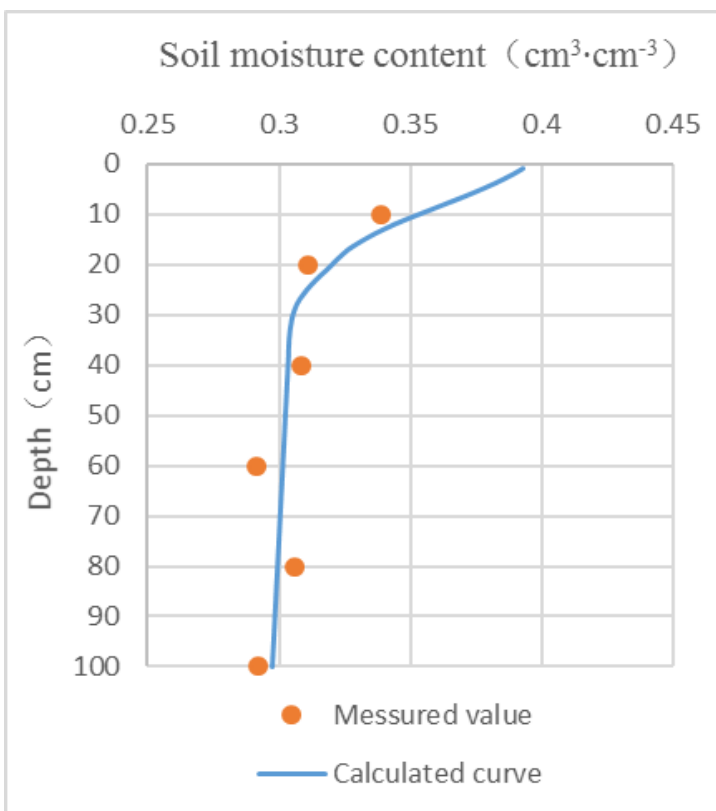

(a) 20 min after rain

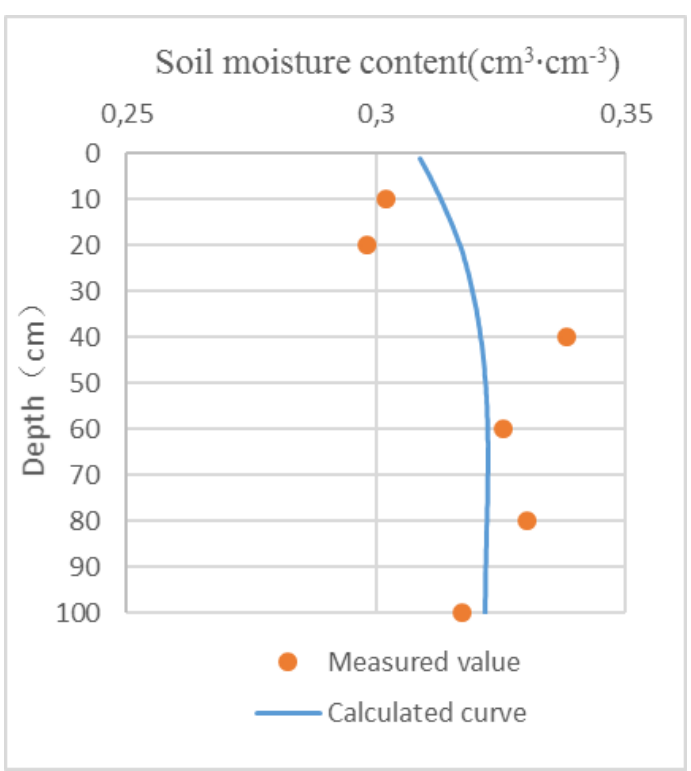

(c) $24 \mathrm{~h}$ after rain

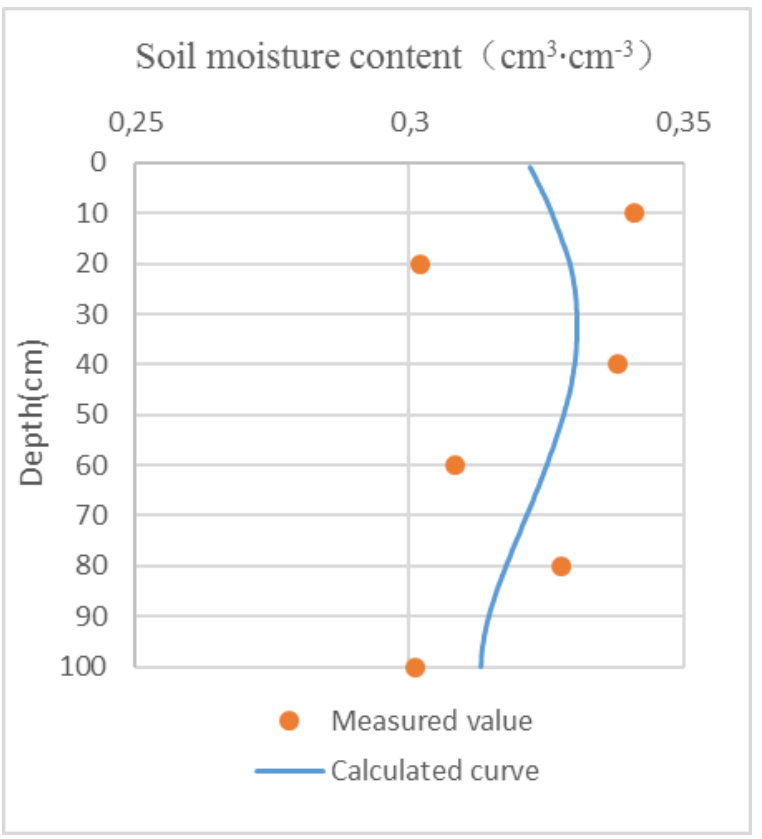

(b) $12 \mathrm{~h}$ after rain

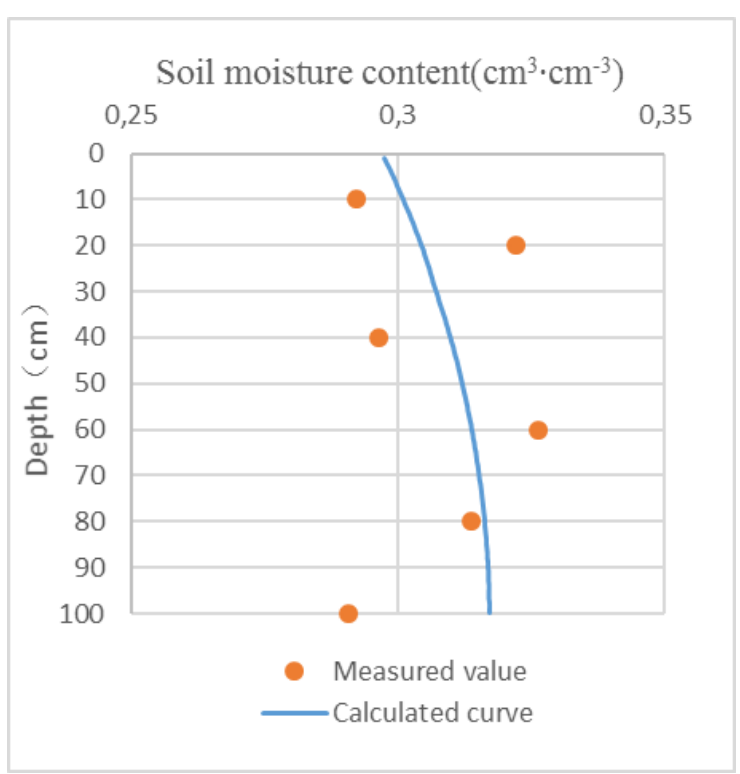

(d) $48 \mathrm{~h}$ after rain

Figure 2. Calculated and measured soil water redistribution after rain for the CK treatment 


\section{Simulation results}

The rainfall with $19 \mathrm{~mm}$ of total rain-water and $1 \mathrm{~h}$ duration occurred on the $22^{\text {nd }}$ of July 2015 was chosen to simulate the soil water distribution at $48 \mathrm{~h}$ after rain. The results was shown in Figure 3. The figure showed that with increasing the amount of biochar, the curves right shifted, especially in the case of the soil layer at a $0-50 \mathrm{~cm}$ depth, which means that the soil water content in the profile was increasing as well. However, below the soil depth of $50 \mathrm{~cm}$, the soil water content changes were not significant, the reason for which is the fact that the biochar was applied to the upper layer of the soil, which made the soil porosity of the upper layer higher than that of the deeper layers. Thus with the depth increase, the soil water content reduced sharply, and with the increase of the amount of biochar applied, the soil water contents were also increasing by a small increment.

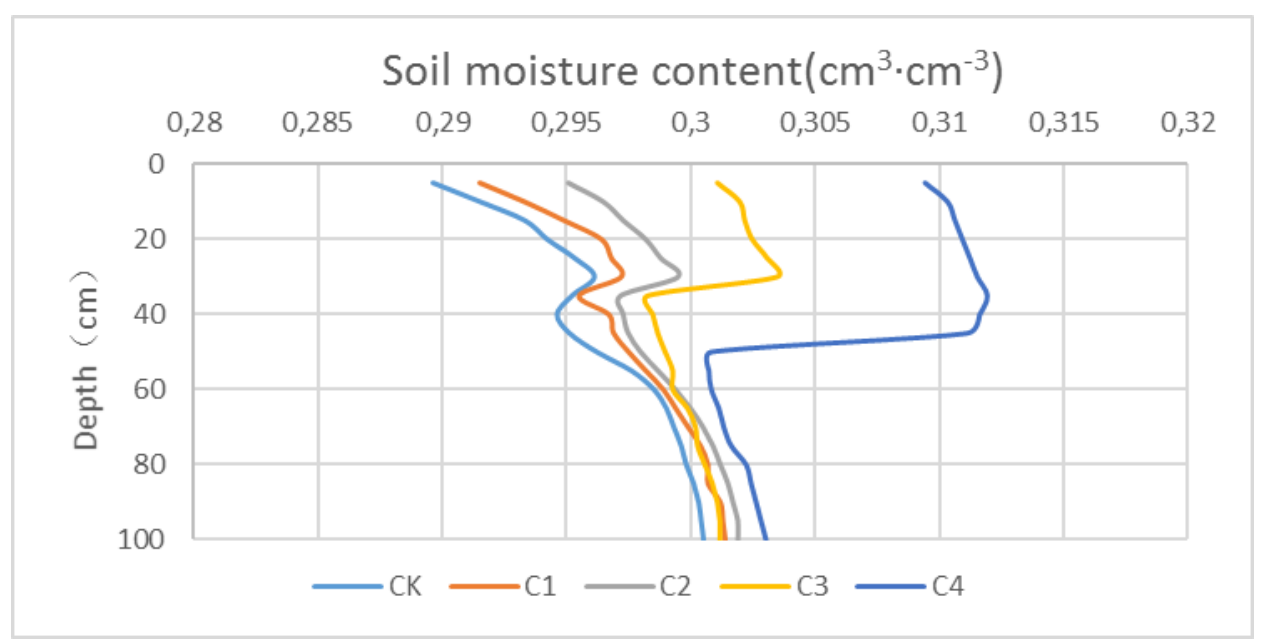

Figure 3. Simulation results of water content in the soil profile for different treatments

\section{Conclusions}

(1) With the increasing amount of biochar applied, the residual soil moisture content and the shape parameter were decreasing, and the saturated soil moisture content and the reciprocal of air inlet value were increasing. The difference between the saturated and residual water content increased with the amount of biochar, which greatly improved the available soil moisture content. Moreover, biochar treatment can improve soil water redistribution conditions, increasing the soil water holding capability in the cultivated layer, which should be beneficial to the growth of crops.

(2) The errors of soil water movement simulation based on the Hydrus-1d software were between $-5.12 \%$ and $9.15 \%$ which is within $\pm 10 \%$. It could be used for soil water movement simulation under biochar application in the black soil region of Northeast China.

(3) The results above have a great significance for soil and water resources utilization and the protection of the black soil region of Northeast China. However, the research was limited to a farmland with a 3 degree slope gradient, thus it is necessary to do similar researches on lands with a 5 degree gradient, because 3 and 5 degree farmlands are the two main types of sloping farmlands in the region. 
Acknowledgements. Many thanks to the support of the Chinese National Natural Science Foundation Project (50479033) and the Project of Chinese National Key Research and Development Program (2016YFC0400101).

\section{REFERENCES}

[1] Cen, R., Qu, Z., Sun, G. et al. (2016): Effect of straw biochar on infiltration law of viscous loam. - Soil and Water Conservation Studies 23: 284-289 (in Chinese).

[2] Chi, H., Bai, Y., Wang, H. et al. (2014): HYRDUS-3D in the soil water infiltration process simulation. - Computers and Applied Chemistry 31: 531-535 (in Chinese).

[3] George, C., Wagner, M., Kücke, M. et al. (2012): Divergent consequences of hydrochar in the plant-soil system: arbuscular mycorrhiza, nodulation, plant growth and soil aggregation effects. - Applied Soil Ecology 59: 68-72.

[4] Lai, X., Liao, K., Zhu, Q. et al. (2015): Feature analysis of soil water leakage and leaching of nitrogen and phosphorus in the typical farmland of Taihu Lake basin based on HYDRUS-1D model. - Resources and Environment in the Yangtze Basin 24: 1491-1498 (in Chinese).

[5] Li, C., Qu, Z., Gou, M. et al. (2014): Effects of biochar amendment on soil water and nutrient utilization and tomato growth. - Journal of Agro-Environment Science 33: 21872193 (in Chinese).

[6] Liu, B., Liu, Y., Zhang, K. (2018): Numerical simulations of water infiltration for various soil textures using HYDRUS-1D. - Agricultural Research in the Arid Areas 36: 140-145 (in Chinese).

[7] Liu, Q., Xie, S. (1998): A study on field soil water balance for summer corn in north China plain. - Journal of Hydraulic Engineering 29: 62-68.

[8] Liu, Y., Hung, J., Ma, Y. et al. (2017): Effect of Biochar Input on Water Transport in Salinized Gray Desert Soil. - Xinjiang Agricultural Science 54: 343-351 (in Chinese).

[9] Liu, Z. (2017): Effects of Different Dosage and Age of Biochar on Soil Water Movement and Solute Transport. - College of Water Conservancy and Architecture. Northeastern Agricultural University, Harbin (in Chinese).

[10] Ma, H., Yang, D., Lei, H. et al. (2011): Application and improvement of Hydrus-1D model for analyzing water cycle in an agricultural field. - Transactions of the CSAE 27: 6-12 (in Chinese).

[11] Mankasingh, U., Choi, P. C., Ragnarsdottir, V. (2011): Biochar application in a tropical, agricultural region: a plot scale study in Tamil Nadu, India. - Applied Geochemistry 26: S218-S221.

[12] Mualem, Y. (1975): A new model for predicting the hydraulic conducticity of unsaturated porous media. - Water Resources Research 12: 513-512.

[13] Mukherjee, A., Lal, R. (2013): Biochar impacts on soil physical properties and greenhouse gas emissions. - Agronomy 3: 313-339.

[14] Novak, J., Busscher, M. et al. (2012): Biochars impact on soil-moisture storage in an ultisol and two aridisols. - Soil Science 177: 310-320.

[15] Oguntunde, P. G., Abiodun, B. J., Ajayi, A. E. (2008): Effects of charcoal production on soil physical properties in Ghana. - Journal of Plant Nutrition and Soil Science 171: 591596.

[16] Qi, R., Zhang, L., Yan, Y. et al. (2014): Effect of biochar on soil water infiltration characteristics in semi-arid area under constant capacity weight. - Journal of Applied Ecology 25: 2281-2288 (in Chinese).

[17] Simunek, J., Van Genuchten, M. T. (1999): Using the HYDRUS-1D and HYDRUS-2D Codes for Estimating Unsaturated Soil Hydraulic and Solute Transport Parameters. - In: Van Genuchten, M. T., Leij, F. J., Wu, L. (eds.) Characterization and Measurement of the 
Hydraulic Properties of Unsaturated Porous Media. University of California, Riverside, CA, pp. 1523-1536.

[18] Simunek, J., Sejna, M., Van Genuchten, M. T. (1996): HYDRUS-2D: Simulating Water Flow and Solute Transport in Two-Dimensional Variably Saturated Media. International Groundwater Modeling Center, Colorado School of Mines, Golden, Colorado.

[19] Tang, Y., Xu, L., Zhang, H. et al. (2011): Application of HYDRUS-1D/2D in process of soil water Infiltration simulation. - Journal of Anhui Agri. Sci. 39: 22390-22393 (in Chinese).

[20] Van Genuchten M, T. (1980): A closed-form equation for predicting the hydraulic conductivity of unsaturated soils. - Soil Science Society of America Journal 44: 892-898.

[21] Wang, S., Zhou, J., Yu, F. et al. (2005): Application of HYDRUS-1D model to evaluating soil water resource. - Research of Soil and Water Conservation 12: 36-38 (in Chinese).

[22] Wang, W., Liu, Y., Kou, X. et al. (2012): EnKF and HYDRUS-1D based data assimilation experiments for improving soil moisture profile prediction. - Journal of Hydraulic Engineering 43: 1302-1311 (in Chinese).

[23] Wang, Y. (2016): Simulation of Soil Water Movement and Solute Transport under the Condition of Applying Biochar in Black Soil Area. - College of Water Conservancy and Architecture, Northeastern Agricultural University, Harbin (in Chinese).

[24] Wei, Y., Liu, Z., Feng, D. et al. (2016): Influences of the biochar on physical properties of the meadow black soil and dynamic changes of soil water after the individual rainfall. - Transactions of the Chinese Society for Agricultural Machinery 47: 201-207 (in Chinese).

[25] Wei, Y., Wang, H., Wu, Y. et al. (2018a): Effect of biochar on soil hydrodynamic parameters under different slopes. - Transactions of the Chinese Society for Agricultural Machinery:1-16.

http://kns.cnki.net.neau.vpn358.com/kcms/detail/11.1964.s.20181127.0728.018.html (in Chinese).

[26] Wei, Y., Zhang, Y., Zhang, Y. et al. (2018b): Influences of biochar's two consecutive years supply on soil improvement and water saving \& yield increasing in sloping farmland of black soil region. - Transactions of the Chinese Society for Agricultural Machinery 49: 284-291+312 (in Chinese).

[27] Xiao, Q., Zhang, H., Shen, Y. et al. (2015): Effects of biochar on soil moisture infiltration, evaporation and nitrate nitrogen leaching in loess region. - Transactions of the CSAE 31: 128-134 (in Chinese). 